habituales confusiones entre $a$ y $o$ y entre $c$ y $t$ (cf. destubieren por descubrieren), también es posible que Hutten, por asociación con la palabra alemana Matte, haya oído (y escrito) hamata ${ }^{5}$. Igualmente notable es la forma machilz en que aparece la palabra maiz: la $l$ es inexplicable (quizá sea simple errata de imprenta), pero la $c h$ bien puede deberse al hecho de que Hutten oía cierto sonido velar entre las dos vocales ${ }^{6}$.

Debo decir, finalmente, que tres palabras han quedado sin solución: gubleny ("gubleny Poblo", p. 52), de la cual no se puede decir siquiera si es alemana o española, waronata (en la frase "... in ein Poblo waronata funden", p. 52) ${ }^{7}$, y el nombre propio Neno (“...wie das Volck im Land Neno und in solcher noth...", p. 55).

Universidad Central de Venezuela.

FEderica De RitTer

\title{
LA OMISIÓN DEL ARTÍCULO DEFINIDO EN EL CANCIONERO DE UNAMUNO
}

En 1933, cuando publicó su "Estilística y gramática del artículo en español", planteamiento nuevo y original del problema del artículo, Amado Alonso proyectaba un trabajo más extenso sobre el mismo tema. En esas páginas se limitó a exponer lo esencial de su concepto, pero en una nota final indicó las investigaciones ulteriores que se proponía llevar a cabo, una de las cuales era el estudio de la omisión del artículo a base de "numerosos análisis estilísticos de pasajes literarios, llegando hasta los casos debidos a una forzada voluntad de estilo". El proyecto, sin embargo, fue abandonado, y el estudio reapareció, sin cambios, en 1934, y de nuevo en los Estudios lingüisticos de $195^{1}$, con una nota adicional en que el autor definía una vez más los problemas que quedaban por examinar, entre ellos "un campo de estudio muy prometedor en la casuística del artículo y de su alternancia con otras formas (ausencia y un)". Y añadía: "Quienes lo emprendan -ya no está para mí- se dejarán sin duda de encararlo normativamente, y procederán con métodos rigurosamente descriptivos según su propio sentimiento del idioma" (p. 181).

${ }^{5}$ A propósito de Hängematte, germanización del americanismo hamaca mediante una etimología popular (hängen 'colgar', Matte 'estera'), dice Georg Friedericr, Amerikanistisches Wörterbuch, Hamburg, 1947 , que la $t$ aparece por vez primera en la palabra holandesa correspondiente (hangmat, hangemat). Si se admite mi hipótesis, habría que concluir que ya Felipe de Hutten, en 1538 , había iniciado ese proceso de etimología popular.

${ }^{B}$ FrIEDERICI, $o p$. cit, menciona varias otras transcripciones antiguas de la palabra maiz: mahiz, majes, mayis, mayes, e incluso marichi. Evidentemente, habia alli un sonido que Hutten transcribió con la -ch-gutural alemana.

${ }^{7}$ J. Friede, en Los Welser, Madrid-Caracas, 1961 , piensa que waronata se refiere a una aldea guaronara. Sin embargo, la posición sintáctica no permite esa interpretación. Podría suponerse guarana (especie de bebida estimulante, según Friedrrici), pero también esto me parece dudoso.

1 Amado Alonso, "Estilística y gramática del artículo en español", $Y K R, 6$ (1933), 189-209; IL, 2 (1934), 144-159; Estudios lingüisticos, Temas españoles, Madrid, $195^{1}$, pp. $15^{1-194 .}$ 
Con el presente estudio, en el cual tratamos de acotar el valor estilístico de la omisión del artículo definido utilizando ejemplos del Cancionero de Unamuno ${ }^{2}$, nos proponemos contestar a la primera de las cuestiones planteadas por Amado Alonso. Sólo limitando el estudio a una obra es posible calibrar la importancia relativa de la omisión.

Un estudio estadístico del vocabulario del Cancionero revela un $11.09 \%$ de artículos definidos contra un $28.28 \%$ de sustantivos, mientras que la lista de García $\mathrm{Hoz}^{3}$ arroja, respectivamente, $10.94 \%$ y $22.10 \%$. De donde se deduce que el $49 \%$ de los sustantivos tienen artículo definido en el lenguaje usual, mientras que en el Cancionero el artículo aparece sólo en un $39 \%$ de los sustantivos ${ }^{4}$. Según las cifras de Tomás $\mathrm{Navarro}^{5}$, el porcentaje de sustantivos acompañados de artículo (definido o indefinido) es de $60 \%$. Ahora bien, si se toma en cuenta que los artículos indefinidos no constituyen sino una parte mínima de los vocablos utilizados (el $0.15 \%$ según García Hoz), el margen entre el porcentaje usual y el unamuniano resulta todavía más grande. Por último, Salvador Fernández, mediante cálculos muy reducidos sobre un solo sustantivo en un texto en prosa de don Miguel, ha puesto de manifiesto que cerca de las tres cuartas partes de las veces este sustantivo va acompañado del artículo $^{6}$. Este porcentaje, sorprendentemente alto, nos lleva a encontrar

${ }^{2}$ Cancionero, Diario poético. (En nuestras referencias, la primera cifra indica el número del poema, y la segunda el verso).

${ }^{3}$ V. García Hoz, Vocabulario usual, común y fundamental. Determinación y análisis de sus factores, Madrid, 1953. en cuanto al Cancionero, los porcentajes proceden de un sondeo efectuado en 35 poemas escogidos con un intervalo fijo de $5^{\circ}$ poemas a partir del núm. $5_{1}^{1}$ (es decir, los núms. 51, 101, 151, etc.). Estos poemas representan, pues, el $2 \%$ de los que integran el Cancionero, y se puede decir que también representan el $2 \%$ del léxico. La selección de poemas según una serie matemática garantiza una buena representación del conjunto de la obra. (Cálculos posteriores efectuados sobre series de poemas paralelos han arrojado porcentajes con variaciones tan mínimas, que resultan desdeñables). En cuanto al lenguaje usual, los porcentajes se han calculado, para los sustantivos, a base de las 4,400 primeras palabras de la lista de García Hoz, Vocabulario usual más anejos ("Relación especial I": palabras de significación restringida, y "Relación especial II": palabras que no figuran en el diccionario), y para el artículo, a base del conjunto de los vocablos de esa misma lista: el ( + la): $3^{6,399}$ + del: $4,774+$ al: $2,321+$ lo: 299 veces $=43,793$ veces. (Los sondeos parciales efectuados en otras series de palabras nos permiten afirmar que los resultados obtenidos para las 4,4 oo primeras palabras sirven para todo el vocabulario).

4 Estas cifras estadísticas no tienen valor en sí. No pueden separarse del comentario. Son, más que nada, un instrumento de trabajo que puede orientar útilmente el análisis estilístico, y, además de ofrecer un material de comprobación que garantiza la total objetividad de los resultados de la investigación, precisan la proporción que toma el fenómeno en el texto estudiado. En otras palabras, confirman aquello que una impresión subjetiva ha descubierto, proporcionándole a la vez un apoyo científico. Sobre la importancia que para el estudio del artículo tienen las estadísticas de frecuen. cia, cf. ya estas palabras de J. WAckernages, Vorlesungen über Syntax, Zweite Reihe, Basel, 1924, apud K. BüHLER, Sprachtheorie, Jena, 1934, p. 308: "Zur Ergänzung ihrer Befunde und zur Illustrierung seines fortschreitenden Einzuges in die Umgangssprache wären wohl einfache statistische Häufigkeitsübersichten wertvoll".

"T. Navarro, Estudios de fonología española, New York, 1945, p. 58.

" Se trata de la palabra ajedrez, en el texto "Sobre el ajedrez". Salvador FERnánDEZ, Gramática española, Madrid, 1951, p. 29o, concluye: "El predominio del artículo sobre las formas sin artículo, según estos pequeños recuentos, es en español muy acentuado". -J. Chicharro de León "Recréations grammaticales: La langue d'Unamuno", 
aún más bajo e interesante el anterior. No disponemos de ningún otro dato estadístico para el lenguaje literario-poético español ${ }^{7}$.

Los resultados del presente estudio serán doblemente limitados. Como nuestros ejemplos proceden sólo del Cancionero, no podemos pretender sacar conclusiones válidas para la poesía en general; y como carecemos de datos comparativos en un mismo nivel de lenguaje, tampoco podemos pronunciarnos definitivamente sobre la originalidad de la omisión del artículo en Unamuno.

El ${ }_{10} 0 \%$ de artículos definidos que falta en el Cancionero se debe, por una parte, al uso excepcionalmente frecuente que hace el poeta de oraciones en que el artículo puede estar normalmente ausente -proposiciones nominales, exclamaciones, aposiciones, etc.-, y por otra, a omisiones debidas sólo a la voluntad del poeta, y que quedan fuera de las previsiones de la gramática. No siempre se ha establecido bien la diferencia entre estos dos tipos de supresión, esencialmente distintos. Pasarla por alto es exponerse a confundir causas y efectos. Así, González Muela, que no parece haber leído la nota adicional de Amado Alonso, atribuye efectos estilísticos a la ausencia del artículo en casos en que esta ausencia se debe a la construcción sintáctica (aposición, frase nominal), a la función oracional de la palabra (vocativo) o a la categoría del vocablo en sí (nombre propio y abstracto), casos que traen como consecuencia automática la omisión del artículo ${ }^{8}$. Sin duda hay que tomar en cuenta la frecuencia de tales casos, pero los ejemplos y sus efectos deben estudiarse en otras secciones, consagradas a la aposición, la frase nominal, etc.

Para poder distinguir entre norma gramatical -colectiva a inconsciente- y procedimiento estilístico -individual y consciente-, y para aclarar, de paso, las deficiencias de clasificación de González Muela y el error de interpretación que de ellas se desprende, conviene analizar brevemente la situación lingüística ${ }^{9}$.

en Cahiers Linguistiques, Gap, 3 (février 1953), p. 14, ha aducido algunos ejemplos de omisión en la prosa de Unamuno, v.gr. "Por puerta falsa de corral se echó al mundo" (Vida de Don Quijote y Sancho), "A luz de vida" (El caballero de la triste figura), "Redoblaba ternura, agradecimiento y piedad" (El espejo de la muerte).

${ }^{7} \mathrm{G}$. BARTH, Recherches sur la fréquence et la valeur des parties du discours en français, en anglais et en espagnol, Paris, 1961, no cuenta esta parte de la oración (véase lo que dice en las pp. 12-13).

${ }^{8} \mathrm{~J}$. González Muela, El lenguaje poético de la generación Guillén-Lorca, Madrid, 1954 , pp. $78-95, \S \S 4,6,3$ y 2 , respectivamente.

9 En efecto, un fenómeno de estilo no puede ser juzgado sino en relación con la norma gramatical. En el dominio de la sintaxis española, M. Criado de Val escribía en su Análisis verbal del estilo, Madrid, 1953, p. 9: "Indudablemente, la orientación hacia el lenguaje ha demostrado ser de mayor utilidad que la versión literaria. Hoy no se concebiría una sintaxis que no recogiera, en sus últimos capítulos, las variantes estilísticas, que, de otra forma, escaparían a su jurisdicción. Tampoco, invirtiendo los términos, sería posible un análisis del estilo que no se sustentara sobre una firme base gramatical". Análisis estilísticos muy precisos, más o menos relacionados con la escuela estilística intuitiva, han conducido, sin embargo, a excelentes resultados. Tales investigaciones permiten ciertamente la caracterización de una expresión, pero no la de un autor. A menudo no tienen cuenta la frecuencia relativa de la expresión dentro del texto, La única garantía en cuanto a su selección, lo mismo con respecto a la lengua que con respecto a la obra de donde se ha tomado, es la propia intuición del investigador. 
En español, el artículo definido puede faltar normalmente en gran número de circunstancias ${ }^{10}$. Los ejemplos del Cancionero que se encuentran en este caso no pueden considerarse como propios del estilo poético de Unamuno.

Si seguimos en su desarrollo el párrafo consagrado por Hanssen a la omisión del artículo ${ }^{11}$, pero empezando por el final, podremos, en este análisis estilístico, dejar a un lado sucesivamente el sustantivo de una frase exclamativa (núm. 19) - “imaternal caricia!” 146.8-, el de una construcción absoluta (núm. 18) - "puente de vida, mocerío" 1933.11-, el de una aposición (núm. 17) - "Dios, supremo pastelero, / amasó. .." 1996.1-, el sustantivo en función predicativa (núm. 16) - "El agua es de tu voz tumba marina" 1359.5; "En el trigal ababol" 1438.1- y el sustantivo acompañado de las preposiciones con, de, en, sin, entre, etc., cuando éstas "introducen complementos de calidad, escasez, abundancia, privación", o "designan cambio de estado o de esencia, materia, situación no definida" (S. Fernández, op. cit., \$ 148, p. 289) - "con virtud de porcelana" 595.5; "el ciego sentido / sin asidero" 1343.8 ; "en bruma de fugaz ensueño" 290.10; "se incorpora en carne de la letra" 104.10; "nos libra de mal / el salto mortal" 935.7; "tejer vela / con hilaza de la entraña" 1696.5 .

Estudiaremos, por el contrario, los casos de sustantivos sin artículo tras las preposiciones que "tienen un valor marcadamente localista y posicional: tras, detrás de, junto a, encima, desde, debajo, hasta, sobre, dentro, algunas veces entre, etc., con las intencionales: a, por, para, contra, y con las instrumentales: con" (S. FERnáNDEZ, § 148, pp. 288-289; HansSEN, $\$ 5^{2}$, núm. 15 ), los sustantivos en función de complemento directo (Hanssen, núm. 14) y los sustantivos sujetos (núm. 19) ${ }^{12}$, casos, todos éstos, que escapan a las normas gramaticales.

Pero la función del sustantivo en la frase no es el único factor que decide la presencia o la ausencia del artículo. También se emplean normalmente sin él -y por lo tanto los descartamos de nuestro estudio- los nombres propios, los abstractos de cualidad, los que designan una materia y los concretos en plural cuyo grado o cantidad están sin determinar ${ }^{13}$.

Sin embargo, la cuestión es aún más compleja, ya que el significado del nombre, así como el de las palabras que lo rodean y sus relaciones mutuas, tampoco son hechos indiferentes. Por ejemplo, a menudo prescinden del artículo, tras una preposición, los nombres que designan partes u órganos del cuerpo - "con mano de luz" 41.9; "en corazón de encina" 679.2-, así como las palabras que indican un lugar en general, v.gr.

10 Creemos, con Chr. BAlley, "Figures de pensée et formes linguistiques", GRM, 6 (1914), p. 463 , que "en matière de langue, «logique» est un terme équivoque". Evitaremos, pues, este término a pesar de las precisiones de L. Lerch, "Zum Gebrauch des Artikels, namentlich beim Abstraktum", ZRPh, 61 (1941), p. 244, nota 1: "Der Logik nach heisst der normalen Funktion des Sprachmittels nach". Preferimos normal, en el sentido de 'conforme a las normas contemporáneas de la lengua'.

${ }^{11}$ F. HANssen, Spanische Grammatik, Halle, 1910, pp. $174^{-1} 7^{6}, \S 52$, núms. $13^{-19}$.

${ }^{12}$ Caso examinado, para la poesía de Aleixandre, por C. Bousoño, La poesia de Vicente Aleixandre, Madrid, 1956, pp. 323-325.

${ }^{3}$ R. Lenz, La oración y sus partes, $3^{\text {a }}$ ed., Madrid, 1935, p. 289; S. Fernández, p. 284; S. Grlr y GAYA, Curso superior de sintaxis española, $2^{\wedge}$ ed., Barcelona, 1948, pp. 215-216; HANSSEN, P. 173. 
casa, palacio, etc. El artículo puede faltar igualmente ante sustantivos que forman una pareja ("Verbundene Substantivpaare") - "en luz y en oscuridad" 588.6; "rindió cáliz y corola" 162.11-, en las proposiciones con dar, echar, hacer, perder, poner, tener y otros verbos - "se me hace fuego el corazón" 1360.4; "le dará sombra la capa" 1269.3-y, en general, en las locuciones que forman una unidad conceptual (frases hechas, refranes, proverbios, etc. $)^{14}$.

Hemos visto cómo González Muela atribuye valor estilístico a casos puramente gramaticales. Salvador Fernández (que también parece ignorar la nota adicional de Amado Alonso) adopta en su Gramática española una actitud extrema a la inversa, al poner en duda que la ausencia del artículo pueda constituir un problema de estilística en el español actuallis. Los ejemplos que damos a continuación constituyen una réplica a esa duda, puesto que escapan a las normas descritas precisamente por Fernández. Representan una gama casi completa de los posibles tipos de omisión que quedan fuera del actual sistema gramatical español. Van agrupados según la categoría del nombre afectado en cada una de las tres funciones ya indicadas (sujeto, objeto directo y sustantivo precedido de preposición), a razón de un nombre tipo para cada categoría. Estos nombres, escogidos por su frecuente empleo en las diversas condiciones gramaticales citadas, son vida, cielo y voz.

Unamuno omite a veces el artículo delante de nombres abstractos que

14 Partes del cuerpo: G. SPRANGer, Syntaktische Studien über den Gebrauch des bestimmten Artikels im Spanischen, Leipzig, 1933, p. 119; Hanssen, p. 175.-Lugar en general: SPranger, p. 119 ; Fernández, pp. 289 y 294.-Parejas de sustantivos: SPRANGer, p. 56; Fernández, p. 316.-Oraciones con dar, echar, etc.: SPRAnger, p. 109.-Frases hechas, etc.: Spranger, p. 109; Fernández, p. 288; Hanssen, p. 175-No pretendemos, claro está, exponer aquí toda la cuestión de la ausencia del artículo definido en español moderno. Simplemente hemos querido recordar los principales casos de omisión nor. mal, así como los factores que la determinan, con el fin de despejar el terreno y preparar el estudio de las omisiones que caen fuera de las normas gramaticales. Un breve examen del libro de González Muela desde este punto de vista demostrará la oportunidad del suscinto resumen que hemos hecho. Cf. también S. Fernández, p. ${ }_{77}^{6}$. Entre las decenas de omisiones citadas por González Muela, sólo tres parecen debidas a la libre elección del autor: "las llamas buscan (x) noche" (p. 92), "( $(x)$ noche tirante reluce" (p. 93) y "(x) alma tarareada goza río suyo" (p. 94).

${ }_{15}$ E. Gamillscheg, "Zum romanischen Artikel und Possessivpronomen", en sus Ausgewählte Aufsätze, Leipzig, 1937, p. 45, ofrece una explicación estilística para algunos casos del francés antiguo, época en que la presencia del artículo no era aún una obligación gramatical: "So kann der Artikel, namentlich, in einer Zeit, zu der die Artikelsetzung noch nicht sprachliche Notwendigkeit ist, suggerierend wirken. La France, neben afrz. France drückt aus: Frankreich, das dir in seiner Grösse, Schönheit, Macht, seiner geographischen Lage bekannt ist. So hebt der bestimmte Artikel das Nomen aus dem übrigen Zusammenhang als gedankliche Einheit heraus, und diese Funktion ist z.B. im Französischen geblieben, als der Artikel nicht mehr ein Mittel der stilistischen Verfeinerung, sondern eine grammatikalische Notwendigkeit geworden war. In Les vins de la France tritt France heute als geographisch und sonstige Einheit hervor, in Les vins de France tritt die Gegenständlichkeit des Nomens zurück". Y p. 44: "Dieser Artikel ist nicht eine sprachliche Notwendigkeit, sondern ein Zeichen stilistischer Verfeinerung des Ausdrucks". S. Fernández, op cit,, p. 276, rechaza la interpretación de Gamillscheg cuando proclama que no cree que la cuestión de la omisión del artículo pueda ser un problema de orden estilístico, y añade: "Si por estilistica entendemos la posibilidad del uso libre de un instrumento lingüistico, manejado con intenciones estéticas o expresivas, cualquier lengua moderna revela mucho más coerción que 
no indican grado o cantidad: "Y en ti se anuda $(x)$ desnuda vida" 502.6; "mariposas / desovaban en torno ( $x$ ) vida informe" 1602.8 ; "Oye la canción de (x) vida" 899.13. Con otras preposiciones y otros sustantivos: "para (x) eterna encarnadura" 12.8; "contra (x) iras de Dios" 1503.3; "dentro de $(x)$ historia" 1660.6 , etc.

Falta asimismo el artículo bastante a menudo ante sustantivos que denotan elementos o seres únicos o individualizados, sobre todo elementos de la naturaleza como cielo, luna, tierra, estrellas, etc., que por regla general se emplean con artículo16: "Castilla a que abraza / (x) cielo bajo su cobijo" 407.10; "hojas de abismo que sellan (x) cielo" 159.4; "y al ver recojerse la estrella / se emboza sobre el verde en (x) cielo" 474.12. Con otras preposiciones y otros sustantivos: "Sobre $(\mathrm{x})$ tierra desdiosada, / ay del alma deshuesada, / que ya no se tiene en pie" 1328.1; "tinieblas por (x) horizonte" 1562.20 , etc.

Finalmente, en muchos casos falta también el artículo ante nombres concretos: "Adán! Adán!" aún en las entrañas / del cielo, (x) voz de Antiguo Testamento / suena como huracán" 1396.16; "Muere quien ve a Dios el rostro, / no el que oye (x) voz de su boca" 1713.2 ; "la tiniebla está encinta de la lumbre, / el silencio de (x) voz" 339.15 var. ${ }^{17}$ Con otras preposiciones: "ten firme el pie sobre (x) rocas" 1643.2 ; "entre (x) brumas en el puerto" 1743.16; "Ganó Legazpi con (x) pluma... las Filipinas" 74.17; "que en (x) ley para los necios paradójica / se fragua con (x) cerebro corazón" $359 \cdot 4^{18}$, etc.

El número de omisiones insólitas es, sin embargo, muy escaso. Para 246 y 219 apariciones de los sustantivos cielo y vida, hemos contado, respectivamente, 41 y 37 casos de falta del artículo. Pocos de ellos desafían de manera indiscutible los postulados de la gramática normativa. Otros son casos vagos, posibles, pero, de todos modos, poco frecuentes, y la mayoría, en fin, no va acompañada normalmente del artículo ${ }^{19}$.

libertad, en ésta no menos que en otras secciones de su estructura. E1 hecho de que unas lenguas diferencien determinadas categorías y sus instrumentos correspondientes no quiere decir que usen de ellas con fines exclusivamente estilísticos".

16 S, Fernández, $\S 15$ o, p. 293: "Cualquiera que sea la función sintáctica que desempeñen, los nombres (propios o comunes) de entes únicos e individualizados en la serie se emplean en general sin artículos: ...Pero el Creador... También la gloria... Lo mismo: el mundo, el universo, la tierra, el firmamento, el cielo, el sol, la luna, las nubes, las estrellas, el aire". Y $\$ 144$, p. 282 : "Los elementos de la naturaleza no forman siempre un campo de sentido con los datos de la situación, pero constituyen lo que podríamos llamar constantes y entran frecuentemente en el discurso en primera mención asociados al artículo..." Lo cual contradice, por consiguiente, al menos para el español, la afirmación de G. GuIllaume, Le problème de l'article et sa solution dans la langue française, Paris, 1919, p. 19, según el cual "les noms d'êtres uniques abstraits ou concrets résistent à l'article". En realidad, los pocos ejemplos citados por Guillaume van desde el Cid hasta el Quijote.

17 Falta esta variante en la edición única del Cancionero.

18 Var. "se fragua con los sesos corazón".

19 He aquí los ejemplos del nombre sin artículo, por orden de aparición en el Cancionero. Para vida: "es su agonía vida que se derrama al pie" 18.4; "ardor de vida" 20.3; "¡ay vida. ..!" 48.17; "la M, / compás de vida" 245.30; "llegar sin vida" 259.3; "que da vida, vida bélica" 289.15; "pan de vida" 312.12; "de vida se me vistió" 327.6; "pasan las olas de espuma, / sal de vida zarandean" 413.12; "en vida que nunca acaba" 417.31; "en ti se anuda desnuda vida" 502.6; "¿es espuma, / o poso de vida tu alma?" 507.8; "sola vivió sola vida" 512.1; "dame. . más peso, / vida de la verdad" 
A menudo es muy difícil saber si la omisión de un artículo es cuestión gramatical o si responde a intenciones estéticas o expresivas. De ahí la necesidad de volver al texto para juzgar cada uno de los ejemplos que citamos. La confusión puede ser tanto mayor, cuanto que no existe ninguna definición rigurosa de las diferentes categorías del sustantivo y, en particular, de los nombres concretos y abstractos ${ }^{20}$. Hecha esta distinción, no resulta fácil decidir si los ejemplos con nombre abstracto están realmente fuera del sistema actual de la lengua. Antiguamente el abstracto podía emplearse sin artículo, y si el uso actual nos hace aceptar el artículo definido ${ }^{21}$, seguimos, sin embargo, encontrando lógico que pueda suprimirse, por la naturaleza abstracta del nombre. Muchas de estas palabras

598.4; "madre del saber de vida" 708.5 ; "madre de vida y saber" 708.6 ; "el fanal de vida" 710,11; "el resorte, / el viejo conforte / de vida y de amor" 816.3; "Oye la canción de vida" 899.13; "Agonía de amor es lucha a vida" 920.1; "vivir vida" 943.10; "Vida, en su muela nuestro Dueño / te muele" 1071.3; "lumbre dadora de vida" 1082.2; "el alma de toda vida" 1085.5; "recuerdos enterrados, vida / tras tierno olvido" 1454,15; "despertar a vida siempre / nueva" 1456.5 ; "Vuelta a empezar nueva vida, / la que acabó" 1456.9; "buscan vida más extática" 1473.8; "que nos da vida y salud" 1497.7; "qué vida agónica" 1504.3; "arte sin vida" 1537.11 ; "calla quieta en muerte en vida / y en hondo reposo olvida" 1574.6 ; "mariposas / desovaban en torno vida informe" 1602.8; "vasos de la esencia / del hondo contento / de pura existencia / de vida que pasa" 1608,13; "que no es de andar al sereno / vida de tantos trabajos" 1614.4; "cuando acaben vida y guerra" 1626.12; "todo. .. da color de vida" 1662.13. - Para cielo: "Huele a cielo de Espa. ña" 51.1; "el alma se me hizo cielo" 76.9 ; "Es un cielo que hace cielo" 146.3; "hojas de abismo que sellan cielo" 159.4; "a cielo descubierto" 181.8; "la tristeza enorme / que cielo, tierra y alma rezumaban" 291.8; "Cielo sin fin de mi celda" 286.1; "soñando cielo" 297.8; "beber cielo" 346.15; "Mas si el sol viene desnudo / cielo de acero a escaldar" 387.5 ; "Cielo del águila bicéfala" 405.13; "posado entre cielo y nava" 407.3; "la Castilla a que abraza / cielo bajo su cobijo" 407.10; "se emboza sobre el verde en cielo" 474.16; "manos que, alas, el cariño / encumbraron cielo arriba" 484.12; "Cielo de la madrugada, / agráciame el despertar" 494.1; "Tierra tu firme sustento, / cielo tu coronación" 539.6; "cielo naciente, pasaba / la brisa" 683.3; "no hay más cielo!" 684.10; "Qué cielo!" 734.1; "cielo romántico y céltico" 769.4; "cielo vasco por corona" 793.3; "que se acerca el temblor de cielo" 811.2; "el alma quiere ser cielo en el cielo" 1088.3 [cita de Lope de Vega]; "el divino llanto, / cielo, que nos traes" 1312.12; "un cacho de cielo de escote" 1913.12; "Bajo ciclo pardo" 1441.1; "Cubren cipreses a las áureas torres, / cielo divino" 1454.6; "Toma tierra el cielo, cielo la tierra" 1454.17; "flotando entre cielo y cielo" 1526.6; "En el techo de un cueva / . . soñó, por cielo, un bisonte" 1563.3; "cielo que no se coma / no es cielo" 1563.5; "se hunde en cielo de sol f́caro" 1565.13 ; "cielo desnudo, / y sobre él no hay otro cielo" 1593.4; "tierra llena de cielo" 1594.5; "con cielo lleno de tierra" 1594.6; "ceñida sólo de cielo" 1668.5; "cielo, vacío perdido!" 1715.8; "bebiendo cielo" 1726.1; "Cielo gris lloviendo hastio" 1739.1; "sol de cielo en primavera" 1751.6 ; "el sol pinta cielo" (inédito). - Ningún nombre concreto aparece un número suficiente de veces para que pueda incluirse con carácter válido en esta confrontación estadística.

${ }^{20}$ Fernández, p. 285, nota 2: "Nunca se ha intentado, que yo sepa, una clasificación gramatical rigurosa de los nombres abstractos. Bajo una misma etiqueta se reúnen las cosas más heterogéneas". E. M. MARTínez AMADor, Diccionario gramatical, Barcelona, 1954, p. 36: "Hay que advertir que en muchas ocasiones la misma palabra puede ser concreta y abstracta"; y p. $3^{\circ} 3^{b}$ : "No son pocos los casos, en todos los idiomas, en que no sólo en la derivación sino también en el significado, alterna el tránsito de voces abstractas a concretas, y viceversa".

${ }^{21}$ F. Hanssen, p. 173: "Abstrakte hatten ursprünglich keinen Artikel". La omisión es, en suma, un retorno al empleo de la lengua antigua. El Cancionero demuestra estar en contra de la evolución descrita por los gramáticos, ya que éstos hacen notar que el articulo se omite cada vez menos delante de nombres abstractos. Según Lerch, 
abstractas, por otra parte, traducen conceptos filosóficos. Con el fin de hacerle expresar nociones y matices más sutiles, se hizo figurar al sustantivo abstracto ya con artículo, ya sin él. A causa de esos tratamientos operados a lo largo de los siglos para adaptar y dar mayor flexibilidad al nombre, los dos procedimientos parecen hoy aceptables y aun naturales. Finalmente, para los sustantivos abstractos suele ser difícil determinar si lo suprimido es el artículo definido o el indefinido, si bien, sea cual fuere la omisión, los efectos producidos son similares.

Después de haber tratado de establecer así una diferenciación entre los casos estilísticos y las ausencias puramente gramaticales, y de haber circunscrito, dentro de lo posible, su importancia numérica y el margen de libertad lingüística en que pueden incluirse algunas de ellas, pasaremos a examinar los efectos.

En el lenguaje corriente, el artículo se omite cuando el nombre expresa un sentido más general y abstracto y representa al objeto o concepto en su esencia más que en su actualidad concreta ${ }^{22}$. Con la omisión como figura estilística, el poeta tiende en primer lugar a extender la calidad de abstracción y generalización a objetos o conceptos que no suelen tratarse así, o que lógicamente no pueden serlo. Los nombres abstractos, casos marginales por excelencia, se prestan a ello en virtud de su misma naturaleza. Sin artículo, sustantivos como vida y muerte expresan, en lugar de accidentes susceptibles de definición concreta, las nociones 'vida' y 'muerte' fuera de toda contingencia, consideradas como fuerzas esenciales, ilimitadas y primitivas. En "mariposas / desovaban en torno (x) vida informe" 1602.8, lo evocado no es una existencia delimitada o un ser vivo,

art. cit., p. 236, la evolución sería la siguiente: "1. die Abstrakta haben gewöhnlich schon den Artikel, aber es bleibt den Dichtern und anderen Autoren noch unbenommen, sie gelegentlich artikellos zu gebrauchen; 2. die Artikellosigkeit schwindet auch in der dichterischen oder sonst gehobenen Sprache. Das Deutsche ist bei der ersten Etappe verblieben; das Französische wäre vermutlich nicht zu der zweiten Etappe fortgeschritten, wenn nicht die Reflexion und die Grammatiker eingegriffen hätten". S. FernÁndez, que cita a Hanssen y a Lerch (con un error bibliográfico en el segundo caso), da a entender (pp. 285 ss.) que el español ha sufrido la misma evolución. Véase también la bibliografía que da el mismo Fernández, p. 286, nota 1, para el español antiguo y clásico.

22 A. Alonso, VKR, 6 (1933), p. 196: "Echando mano de la pareja de conceptos filosóficos esencia-existencia, diremos que el nombre con artículo se refiere a objetos existenciales y sin él a objetos esenciales. Con artículo, a la cosas; sin él, a nuestras valoraciones objetivas y categoriales de las cosas. Esta alternancia significativa se cumple tanto con los nombres correspondientes a conceptos que tienen extensión variable, como con los nombres de objetos individuales y con los abstractos... El nombre sin artículo apunta directamente a la esencia de lo nombrado, a nuestra valoración subjetiva del objeto, a su rango, a su quid". Y p. 198: "La ausencia de artículo corresponde al carácter puramente cualitativo con que el objeto es nombrado; denuncia una referencia al quid o esencia del objeto", etc. -GILI GAYA, p. 216: "Los concretos en singular, que no tengan carácter colectivo, adquieren cierto sentido general o abstracto cuando se usan sin determinación". S. Fernández, pp. 278-279: "la falta de artículo y de pronombre destaca también la dimensión cualitativa de las cosas, o, más bien, desactualiza el concepto y lo presenta en su pura esencia". GonzÁlez Muela, p. 81: "Vocativo y aposición apuntan, al ir sin artículo, a la esencia del nombre a que se refieren", y p. 92: "El sustantivo poético se nos ha dibujado, merced al estudio de su abundante uso sin artículo, como una esencia abstraida y amorosamente contemplada". 
sino algo así como el plasma, la energía confusa de la vida. $\mathrm{Y}$ en "cura (x) muerte la luz" 543.4, no se trata del instante en que el hombre muere, sino de una especie de larga enfermedad que alienta en él. Este matiz es particularmente notorio en los casos en que muerte, sin artículo, y vida, con él, por ejemplo, aparecen yuxtapuestos: "así quedó / . . su vida en (x) muerte" 1619.14; "de la vida (x) muerte brota" 1689.7. La paradoja que cada una de estas proposiciones constituiria si muerte estuviese acompañada de artículo definido, queda estilísticamente resuelta con la omisión del artículo. Sólo porque la noción de muerte escapa a toda determinación en el tiempo y en el espacio, puede la vida continuar en el estado de muerte, y la muerte, eterna, puede nacer de la vida.

Pero ésta no es, ciertamente, la única explicación. El nombre sin ar. tículo tiende a expresar una noción más pura. Con la omisión del artículo, el poeta hace perder a las palabras abstractas sus reminiscencias del lenguaje filosófico, adecuándolas así a la poesía. En este punto, entre otros, difiere de la filosofía la poesía conceptual de Unamuno. He ahí por qué Lerch y más tarde Fernández (este último con reservas) pudieron comprobar que los poetas, al contrario de los prosistas, omiten aún hoy el artículo delante de los nombres abstractos ${ }^{23}$.

Esos mismos efectos se observan cuando se trata de nombres de seres únicos o individualizados. En "cuando te dore la aurora / en (x) sol reciente las manos" 1433.8 , sol designa una especie de sustancia que sirve para dorar, y noche, en "con tinta / de (x) noche que no se borre" 254.9, es la materia de que está hecha la tinta indeleble. En "Se hunde en cielo de $(x)$ sol Ícaro" 1565.13 , "el silencio de $(x)$ noche" 48.1 y "la copa de $(x)$ noche de la encina" 760.1 , los mismos nombres sol y noche no expresan sino una cualidad del cielo, del silencio y del follaje de la encina.

Si esta desindividualización es absolutamente evidente cuando el sustantivo va precedido de una preposición -es, desde luego, el caso más frecuente-, el hecho resulta menos notorio cuando el sustantivo es sujeto u objeto directo. Pero, incluso en estas funciones, se tiene la impresión de que la idea de cielo, por ejemplo, pierde un poco de su contorno preciso, para transformarse, ya en masa o volumen - "hojas de abismo que sellan (x) cielo" $1_{59} 5$-, ya en superficie, siempre sin perfilar - "el sol pinta (x) cielo" 24 . Gracias a la ausencia del artículo, muchos versos se salvan así de la trivialidad de la descripción. Bastaría un artículo definido en "polvo de oro de (x) sol andaluz" $5^{60.2}$ para rebajar al luminoso polvo de oro de Andalucía a un total prosaísmo geográfico. Y con artículo, la visión cósmica de "a sombra de $(\mathrm{x})$ tierra el altar" 1371.4 sería una escena desmañadamente anecdótica ${ }^{25}$.

Una impresión análoga se desprende de los ejemplos con nombre concreto. En "La tiniebla está encinta de la lumbre, / el silencio de (x) voz" 333.15 var., voz viene a ser una sustancia confusa y primitiva, al igual

${ }^{23}$ Lerch, p. 236; FernÁndez, p. 286, nota 2, Cf. supra, nota 21.

${ }_{24}$ La última cita procede de un poema inédito de Unamuno que debiera figurar en el Cancionero. En nuestra tesis sobre el Cancionero incluimos el texto completo de esta composición.

${ }^{25}$ Véase supra, nota 15 , la interpretación que hace Gamillscheg de les vins de la France y les vins de France. 
de lumbre, a cuyo nivel ha sido atraída gramaticalmente con la omisión del artículo. La introducción del artículo definido delante de voz en dos ejemplos ya citados - “Adán! Adán!» aún en las entrañas / del cielo (x) voz de Antiguo Testamento / suena como huracán" 1396.16; "Muere quien ve a Dios el rostro, / no el que oye $(x)$ voz de su boca" 1713.2- podría destruir el misterio grandioso que los impregna. Y piénsese en el efecto desastroso que haría el artículo - suscitando una imagen demasiado realista- en la siguiente metáfora que refleja el surgir del fervor místico en una Santa Teresa: "la fragua / de su entraña a que (x) dedos / del Señor encendieron" $1493.9^{26}$.

La omisión del artículo definido ante nombres concretos aleja de la realidad y lleva directamente del plano de la anécdota al de la "leyenda". Los contornos de los objetos tienden a difuminarse, incluso cuando hay determinantes muy precisos, como en el último ejemplo citado. Los objetos se desrealizan, sin que por ello los nombres que los designan queden reducidos a un mero sentido figurado. En "ojo maternal del río / sueña en (x) mar oscuridad / de abismo" 347.14, una impresión de sueño y de imagen borrosa se desprende de las profundidades marinas; $y$ en "a qué luz de íntimo fuego / te trazó ( $\mathrm{x}$ ) segura mano / de soñador soberano" 1562.22 , el trazado de las pinturas prehistóricas, llevado a cabo por una mano desconocida pero infalible, es mágico porque el poeta cuida de borrar, con la omisión del artículo - de varios en estos versos-, Ia idea demasiado precisa que podría dejar cada una de las palabras por él empleadas. Pero es obvio que el mar sigue siendo mar, y la mano, mano.

En el Cancionero, Unamuno describe muy poco. Reduce lo concreto, pero también lo transpone. La omisión del artículo, al ayudar a crear una atmósfera de sueño y de fantasía, favorece esta transposición, y contribuye a plasmar unos versos estilizados, casi esquemáticos, imagen escrita de un dibujo moderno y primitivo a un tiempo:

$$
\begin{aligned}
& \text { Lampazo aterrado al suelo, } \\
& \text { en torno (x) trébol tirita } \\
& \text { y virginal margarita } \\
& \text { abre }(x) \text { párpados al cielo }(966) \text {. }
\end{aligned}
$$

Más de un verso del Cancionero adquiere, con esa omisión, un aire de proverbio. Aquí el proceso de abstracción y el consiguiente carácter de generalidad son más claros aún: "Hablando se entienden (x) hombres" 19.13; " $(\mathrm{x})$ ceniza / ha de abonar (x) nuevas frutas" 1477.3, etc. ${ }^{27}$. Así, a

${ }^{26}$ Aquí, sin embargo, la omisión parece estar facilitada por el plural dedos.

${ }_{27} \mathrm{~V}$. Bröndal, Les parties du discours. Partes orationis. Etude sur les catégories linguistiques, Copenhague, 1948, p. $1_{57}$ : "Les proverbes enfin, comme on sait,

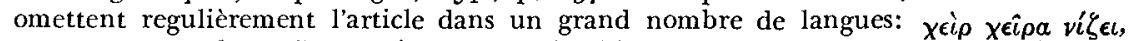
manus manum lavat. Pauvreté n'est pas vice. Voir dans cet usage un simple archaïsme, donc y voir un héritage d'une période plus ancienne qui n'employait pas l'article, est sans doute une explication... insuffisante... [cf. también nuestra nota 21, supra]. Il doit y avoir un facteur positif, agissant constamment dans toutes les langues, qui explique cette omission régulière dans ce genre d'expressions. Celui-ci doit être cherché dans le caractère même des proverbes. Les proverbes sont des échantillons de sagesse 
través del tiempo, lo arcaico y lo moderno se vuelven a encontrar. En estilística todo se repite ${ }^{28}$.

Pero no siempre bastan estas razones. La elisión del artículo no se debe únicamente a la búsqueda de matices significativos ni siquiera como meta primordial. Varios ejemplos nos habían puesto ya sobre aviso. Existen casos en que se omite el artículo definido sin que pueda haber realmente abstracción ${ }^{29}$. Así ocurre con ciertos nombres concretos debidamente particularizados, ya por un complemento determinativo, ya por una oración de relativo: "Bajo cielo pardo / (x) pobre flor del cardo / . . . sueña con erizo" 1441.2; "compuso... en lo alto... / (x) faro del celeste puerto" 1719.12; "aun me alcanza / luz de luna / Ilena de (x) sol que se murió en la mar" 840.17. (La gramática nos enseña expresamente que, en esos casos, el artículo se emplea por regla general para introducir al sustantivo $)^{30}$.

Esta imposibilidad de abstracción es aún más manifiesta cuando, paralelamente a un nombre sin artículo, se emplea otro de la misma categoría con artículo definido: "el Sol se ha puesto naciente, / . ..(x) luna llena se ha hecho nueva" 506.9; "se escapa a saltos el canguro; fluye / (x) ondulante serpiente entre la yerba" 102.2. No es menos cierto que tenemos una impresión de desnudez y de generalización análoga a la observada en los primeros ejemplos. Aquí la poesía viene en auxilio de la lógica.

Por otra parte, el artículo no se omite sólo para que la frase cobre un carácter de generalidad, sino también, muchas veces, por razones de pura forma: de sonoridad, de ritmo, o para poner en relieve cierta palabra. A

populaire de caractère universellement valable. Il ne faut donc pas que les notions ou les sujets qu'ils mentionnent semblent être présentés comme ne valant que dans tel ou tel cas; il est au contraire d'une importance décisive que l'expression ait un caractère de généralité aussi net que possible. Ceci pourrait être indiqué au moyen de pronoms indéfinis de nature généralisatrice (chaque, quiconque, etc.). Un effet analogue peut cependant être obtenu, d'une manière plus populaire, en posant simplement la notion dans son objectivité immédiate. Or ceci a justement lieu -comme les exemples précédents l'ont montré- au moyen de l'omission de l'article. Celle-ci s'accorde donc bien tant avec le caractère populaire et archaïque des proverbes qu'avec leur caractère général". El gran número de refranes que hay en el Cancioneró confirma, por otra parte, la predilección de Unamuno por este tipo de expresión. La ausencia del artículo en los refranes era uno de los puntos previstos por Amado Alonso para el estudio largo que no llegó a terminar.

28 Wackernagel, op. cit., p. 148: "Ähnliche Vermeidung des Artikels wie in der Dichtung lässt sich am Sprichwort beobachten. Auch dieses hält damit vorgeschichtliche Ausdrucksweise fest; aber was bei den ältesten Sprichwörtern bewahrte Altertümlichkeit war, mag in andern Fällen auf Nachahmung des Alten beruhen und konnte um so eher als Stileigentümlichkeit des Sprichworts gelten, weil dadurch das Bedürfnis nach Knappheit des Ausdruckes befriedigt wurde".

${ }_{29}$ BüHLER, op. cit, p. 306: "Aber das Verwunderliche liegt. .. anderseits an den Bedingungen, unter denen er [el autor] auf den Gebrauch des bestimmten Artikels verzichtet, trotzdem etwas Bestimmtes genannt wird".

3a S. FERnÁnDEz, p. 314: "lo primero [la introducción del artículo] ocurre cuando se agrupan con el nombre complementos nominales, adjetivos o preposicionales, o se acumulan a él ampliaciones oracionales introducidas por un pronombre relativo. Este género de complementaciones aisla una clase así caracterizada de individuos, pero también un solo individuo, dentro de la serie de cosas fungibles, o pertenecientes a una especie o a un género común, representadas por un nombre apelativo, y en este último caso especialmente, el nombre suele adoptar el artículo, cualquiera que sea su función sintáctica". 
menudo, la omisión es resultado de una reacción en cadena. La proximidad de uno o varios nombres sin artículo suele acarrear la ausencia de un artículo definido allí donde gramatical o lógicamente se hubiera requerido. El complemento determinativo puede influir sobre el nombre por él determinado - "baja / del azul derretido (x) unción de noche / la agonía solar" $1627 \cdot 7-$, el objeto directo sobre el sujeto -"pues (x) temblorosas entrañas / vertían sonoro llanto" 611.7-, un complemento circunstancial y un objeto directo sobre un nombre complemento determinativo en la misma oración - "y al pie de $(x)$ cruz que entre silvestres flores / velaba paz final" $1602.2-$, o bien un objeto directo y su complemento determinativo sobre el sujeto o sobre un complemento circunstancial - "(x) Ojo maternal del río / sueña en ( $x$ ) mar oscuridad / de abismo" 347.14 . No es la relación gramatical o psicológica, variable y heterogénea, lo que motiva la omisión, sino el aspecto general de la frase, cierto ritmo interior. Para incorporarse a un esquema rítmico, el sustantivo debe acoplarse a sus leyes, y puede tener que prescindir de su introductor normal, al igual que los otros sustantivos. De la misma manera, puede aparecer sin artículo por razones métricas, pero nada, en esta ocasión, nos permite juzgarlo. En el poema siguiente, por ejemplo:

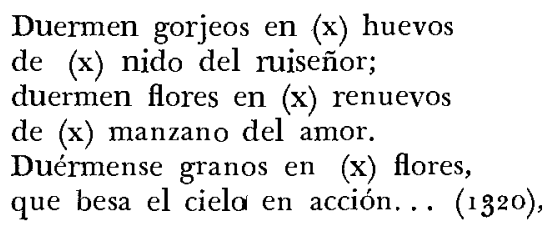

las razones de las ausencias de artículo son difíciles de discernir. No parece que podamos interpretarlas como búsqueda de matices significativos. Imposiciones de métrica podrían ser el punto de partida para explicar la omisión ante huevos, renuevos e incluso ante flores. Pero chay alguna razón que obligue a suprimir el artículo delante de nido y de manzano, manteniéndolo, en cambio, ante ruiseñor y amor?

Despojando al nombre de su artículo, Unamuno consigue, en parte, el verso apretado que desea en su Poética ${ }^{31}$. Al suprimir los vocablos no indispensables -entre ellos los artículos-, el poeta elimina del verso no pocas palabras átonas; y los sustantivos, al acercarse unos a otros, provocan una continuidad rítmica que el rigor del pensamiento lógico o el realismo de la descripción no siempre permiten, o, cuando menos, hacen muy difícili2. Esto se observa, sobre todo, en aquellos versos en que se acumu-

${ }^{31}$ Recordemos aquí solamente el poema tan citado de Poesias (pp. 10-11), "Credo poético", y, en el Cancionero, el núm. $5^{21}$, por ejemplo.

${ }^{32}$ Lerch, art. cit., p. 249, pensaba ya en una explicación rítmica para ciertos tipos de omisión en francés: "Man könnte ferner versucht sein, die Verallgemeinerung des Types tous les hommes usw., rhythmisch zu erklären: tuot usw. ist als affektgetragenes Wort akzentuiert, und auch das folgende Substantiv trägt einen Akzent; nun wird aber die unmittelbare Aufeinanderfolge zweier Tonstellen tunlichst vermieden (tous hommes ist rhythmisch ungünstig). Daher sagt man im Romanischen auch nicht ${ }^{*}$ les tous hommes usw., im Deutschen nicht *die alle Menschen (sondern alle die Menschen) und im Englischen nicht *the all days", etc. (La comparación de los ejemplos demues- 
lan nombres sin artículo, sin adjetivo y sin ningún otro complemento. La serenidad de los siguientes pasajes se debe, ante todo, al ritmo obtenido gracias a esa ausencia: "Se perdió con paso leve / de paloma sobre tierra, / se derritió como nieve / de verano" 380.10 ; "brizaba / el sueño a mariposa / que en capullo soñaba / con capullos de rosa" 1580.5 ; "Oh muertes de mi vida / cifradas en anillo / de oro donde se anida / recuerdo que es castillo / de sueños" $1746.1-5^{33}$. (Ejemplos que demuestran lo gratuito del frecuente reproche que se hace a Unamuno de tener un verso duro, áspero y sin musicalidad. Las omisiones del artículo no son hiatos, sino que facilitan un encadenamiento más íntimo de palabras e ideas. Don Miguel consigue así el ritmo "denso, pero fluido" que él mismo preconizaba) ${ }^{34}$.

Un sustantivo no introducido por un artículo, cuando normalmente lo está, cobra considerable vigor. Aislado y puesto de manifiesto, recupera su plenitud y su prestigio primitivo de fuente y último sedimento del lenguaje ${ }^{35}$. Y tanto mejor si a un tiempo faltan artículo, adjetivo y verbo conjugado, como a menudo ocurre en el Cancionero. La supresión del artículo no es sino un medio entre otros muchos de llegar a una máxima desnudez y concentración.

Como es natural, el estudio de este único aspecto de la poesía de Unamuno no puede conducir, sin más amplias perspectivas, a conclusiones terminantes sobre el Cancionero, pero pone ya de manifiesto que esta poesía es más moderna de lo que se ha creído ${ }^{36}$, bastante menos dura de lo que se ha afirmado, y que es, por lo menos, tan poética como metafísica. Un estudio integral del Cancionero, que esperamos concluir en breve, nos permitirá fundamentar ampliamente estas primeras deducciones.

Rijksuniversiteit, Gent.

Josse DE KOCK

tra, de todos modos, cuán relativas son estas interpretaciones, y la imposibilidad de generalizarlas).

ss En estos casos de acumulación no hay, la mayor parte de las veces, más que un sustantivo en que la ausencia del artículo es "anormal".

${ }^{8 *}$ Cf. carta inédita de Unamuno a José María Quiroga Pla (8-I-29): "En efecto, el Cántico de Jorge Guillén es mucho más maduro que otras cosas que de él conocía, y de más acabado ritmo. Ahora que ese modo tan elíptico y disociativo me fatiga a las veces y no siento impulso a esforzarme. Prefiero lo denso, pero fluido; el agua corriente es más densa que los témpanos que flotan en ella".

35 GONZÁl.fz Muela, pp. 93-94: "La cualidad virtual y quintaesencia del sustantivo poético da a veces a la frase el aspecto característico que a nuestros oídos ofrecen las lenguas primitivas".

${ }^{36}$ Para situar mejor la poesía de Unamuno en el panorama de la moderna poesía española, sería interesante comparar el Cancionero con otros libros poéticos contemporáneos sobre puntos tan precisos como éste, En su Gramática, S. Fernándfz hace una breve investigación sobre el Cántico de Jorge Guillén, que en comparación con la que dedica a Unamuno (cf. supra, nota 6), resulta tan sorprendente como prometedora. Véase también, en cuanto a Guillén, J. M. VALverde, Estudios sobre la palabra poética, Madrid, 1952, p. 173. 